\title{
DEPENDÊNCIA QUÍMICA E TRABALHO VOLUNTÁRIO: AJUDA AO OUTRO OU CONTINUAÇÃO DA REABILITAÇÃO?*
}

\author{
ADDICTION AND VOLUNTEER: HELP EACH OTHER \\ OR CONTINUE REHABILITATION?
}

PÂmela Koch ${ }^{1}$ e Amanda Saraiva AngonesE ${ }^{2}$

Recebido em: 28/03/2015

Aprovado em: 11/11/2015

\section{RESUMO}

Poucas pessoas estão dispostas a se doar frente a uma realidade já vivenciada, principalmente quando este é um fato doloroso de ser lembrado. Sendo assim,o presente estudo teve como objetivo principal entender os motivos que levam um ex-usuário de drogas a se voluntariar em uma comunidade terapêutica. Buscou também verificar quais são as dificuldades encontradas pelo trabalhador voluntário e suas emoções frente ao trabalho voluntário. Para isso, foram entrevistadas cinco pessoas do gênero masculino, ex-usuários de drogas ilícitas, que estavam trabalhando em uma comunidade terapêutica voluntariamente. Metodologicamente, foi utilizada a pesquisa qualitativa com análise de conteúdo, tendo como instrumento para a coleta de dados uma entrevista semiestruturada. A partir da análise dos relatos dos participantes,foi possível perceber que a sua motivação consiste em ajudar o outro. Ao mesmo tempo, contudo, o voluntariado também é visto pelos entrevistados como mais uma forma de continuar o seu tratamento, que origina sentimentos como espiritualidade e reconhecimento. Já as principais dificuldades encontradas por estes trabalhadores estão interligadas aos relacionamentos interpessoais e ao fato de ter de lidar com os próprios sentimentos frente ao outro.

Palavras-chave: Dependência química; Trabalho voluntário; Comunidades terapêuticas; Motivação.

\begin{abstract}
Few people are willing to donate facing a reality already experienced, especially when it is a painful fact to remember. Therefore, this study aimed understand the reasons of an exdrug user to volunteer in a therapeutic community. It also sought find what are the difficulties faced of the volunteer workers and the feelings of the volunteer work. For this, five male people have been interviewed, ex-users of illicit drugs, that were working voluntarily in a therapeutic community. Methodologically, was used the qualitative research with content analysis, using as instrument for collection of data a semistructured interview. From the analysis of the participants report, was possible realize that their motivation is help others. At the same time, however, the volunteering is seen by the interviewees as a way to continue their treatment, which leads to feelings of spirituality and recognition. While the main difficulties found are linked to interpersonal relationships and how to handle with their feelings facing the other.
\end{abstract}

Keywords: Addiction; Volunteer work; Therapeutic communities; Motivation.

*Trabalho de Conclusão de Curso apresentado como pré-requisito para a obtenção do título de Graduada em Psicologia, da Universidade do Oeste de Santa Catarina (UNOESC), Unidade de Pinhalzinho.

${ }^{1}$ Acadêmica do curso de Psicologia pela UNOESC, Brasil. E-mail: pame_koch@hotmail.com.

${ }_{2}^{2}$ Psicóloga e Professora do curso de graduação em Psicologia da UNOESC (Universidade do Oeste de Santa Catarina), Brasil. Especialista em Psicologia Hospitalar pelo Hospital de Clínicas de Porto Alegre/UFRGS (Universidade Federal do Rio Grande do Sul), Pós-graduada em Saúde Mental Coletiva pela UNOESC. E-mail: amanda.angonese@unoesc.edu.br. 


\section{Introdução}

A Organização Mundial de Saúde (OMS) define a dependência química como o estado psíquico e algumas vezes físico resultante da interação entre um organismo vivo e uma substância, caracterizando-se por modificações de comportamento e diversas outras reações que sempre incluem o impulso a utilizar a substância de modo contínuo ou periódico com a finalidade de experimentar seus efeitos psíquicos e, algumas vezes, de evitar o desconforto da privação, conforme a Universidade Aberta do Sistema Único de Saúde (UNA-SUS), [20--]. Segundo a Classificação de Transtornos Mentais e de Comportamento (CID-10) (1993), a dependência é um conjunto de fenômenos fisiológicos, comportamentais e cognitivos, em que o uso de uma ou mais substâncias alcança uma prioridade muito maior para o indivíduo do que outros comportamentos que antes tinham um maior valor.

O objetivo principal deste artigo foi entender os motivos que levam um ex-usuário de drogas ase voluntariar em comunidades terapêuticas. Este estudo buscou, assim, verificar os motivos atrelados à busca do trabalho voluntário,bem como as dificuldades enfrentadas pelo trabalhador voluntário e os sentimentos inerentes a esse processo.

O ex-usuário de drogas que escolhe trabalhar voluntariamente em uma comunidade terapêutica com dependentes químicos em tratamento estará sujeito a se deparar com uma realidade vivenciada por ele anteriormente, assim como poderá ter de enfrentar situações em que se sentirá desvalorizado e/ou desconfortável e dificilmente contará com apoio psicológico, tendo, portanto, de enfrentar suas dificuldades sozinho. Também estará longe de sua família e do conforto do lar, não podendo (dependendo da comunidade escolhida) se casar e ter filhos, de modo que terá de viver com o vínculo afetivo apenas da comunidade terapêutica.
Entender os motivos que levam um ex-usuário de drogas a buscar o voluntariado, mesmo este sabendo que poderá enfrentar uma realidade que já vivenciou, é de suma importância, pois existem poucas pesquisas sobre este assunto e, muitas vezes, os voluntários não têm alguém que os escute e os entenda, de forma que acabam guardando para si as suas angústias e emoções. O principal motivo para a escolha deste tema foi que, após o contato com dois jovens ex-usuários de drogas e que trabalham voluntariamente em uma comunidade terapêutica, começou-se a refletir sobre o que os motiva a, sem nenhuma remuneração, escolher entrar em contato com situações já vivenciadas, sabendo que isso poderá mobilizar sentimentos como a angústia, por exemplo.

\section{Fundamentação teórica}

\subsection{Dependência química}

"A droga é apenas um dos fatores da tríade que leva à dependência, os outros dois são o indivíduo e a sociedade na qual o indivíduo e a droga se encontram" (FONSECA; LEMOS, 2011, p. 25-26).

O consumo de drogas sempre existiu no mundo, não sendo um fenômeno novo como muitas pessoas pensam, mas uma prática milenar e universal. Porém, segundo Pratta (2009, p. 203), é importante pontuar que os hábitos e costumes de cada sociedade é que direcionavam o uso das substâncias em rituais, festas e cerimônias coletivas, caracterizando um consumo que era restrito a pequenos grupos, diferentemente dos tempos atuais, em que esse uso ocorre em quaisquer circunstâncias e por pessoas de diferentes grupos e realidades.

Segundo o Manual Diagnóstico e Estatístico de Transtornos Mentais (DSM - IV, 2002, p. 208): 
A característica essencial da dependência de substância consiste na presença de um agrupamento de sintomas cognitivos, comportamentais e fisiológicos indicando que o indivíduo continua utilizando uma substância, apesar de problemas significativos relacionados a ela. Existe um padrão de autoadministração repetida que geralmente resulta em tolerância, abstinência e comportamento compulsivo de consumo da droga.

Ainda segundo o DSM-IV (2002), a dependência é definida como um agrupamento de três ou mais dos seguintes sintomas, ocorrendo em um período de 12 meses:

1. tolerância, definida pela necessidade de quantidades progressivamente maiores da substância para obter a intoxicação ou o efeito desejado,ou pela acentuada redução do efeito com o uso continuado da mesma quantidade de substância;

2. abstinência, manifestada por quaisquer dos seguintes aspectos:Síndrome de abstinência característica da substância; A mesma substância (ou uma substância estreitamente relacionada é consumida para avaliar ou evitar sintomas de abstinência);

3. a substância é frequentemente consumida em maiores quantidades ou por um período mais longo do que o pretendido;

4. existem um desejo persistente ou esforços malsucedidos no sentido de reduzir ou controlar o uso da substância;

5. muito tempo é gasto em atividades necessárias para a obtenção da substância (por exemplo, consultas a vários médicos ou longas viagens de automóvel), na utilização de substância (como fumar em grupo) ou para se recuperar de seus efeitos;

6. importantes atividades sociais, ocupacionais ou recreativas são abandonadas ou reduzidas em virtude do uso da substância;

7. o uso da substância continua, apesar da consciência de ter um problema físico ou psicológico persistente ou decorrente que tende a ser causado ou exacerbado pela substância (por exemplo, uso atual de cocaína, embora o indivíduo a reconheça como indutora de sua depressão, ou consumo continuado de bebidas alcóolicas, embora o indivíduo reconheça que uma úlcera piorou devido ao consumo do álcool).

Existem diversos fatores de risco envolvidos no surgimento da dependência química. Dentre estes, destacam-se os fatores: biológicos, como a predisposição genética, a capacidade de tolerância do cérebro, a capacidade de metabolização do corpo e a natureza farmacológica da substância; psicológicos, como os distúrbios do desenvolvimento, as morbidades psiquiátricas, os problemas de comportamento, a baixa resiliência, as limitadas habilidades sociais e a expectativa positiva quanto aos efeitos da substância de abuso; e os fatores sociais, como a estrutura familiar, a escolaridade, a exclusão e a violência social, a pressão do grupo para o consumo e o ambientenão saudável com características que podem levar/estimular aoconsumo (MARQUES, 2006). Segundo Fonseca (2011), todas as drogas capazes de causar euforia e alívio da dor têm uma característica em comum: elas liberam dopamina, pois atuam de maneira diferenciada no circuito de prazer ou recompensa. 
Relacionada à dependência química, há o policonsumo de Substâncias Psicoativas (SPAs), que é o consumo concomitante ou consecutivo de diferentes drogas lícitas e/ou ilícitas. Este policonsumo está se tornando regra entre os usuários.

\begin{abstract}
A associação de substâncias pode estar relacionada à busca de maximização de sensações percebidas como prazerosas pelo usuário, minimização de efeitos relacionados à intoxicação e abstinência e também pode refletir a disponibilidade de drogas e os padrões de consumo próprios de meios ou contextos específicos. Em qualquer desses cenários, é fundamental que o poliuso seja detectado e considerado tanto nas abordagens psicoterápicas quanto nas farmacológicas nos diferentes níveis de atenção (AZEVEDO, 2011, p. 119).
\end{abstract}

\subsection{Comunidades terapêuticas}

Segundo Fracasso (2011), em agosto de 1959, em Santa Mônica (Califórnia), foi fundada a primeira comunidade terapêutica, chamada Synanon, por Charles (Chuck) Dedrich, um dependente de álcool em recuperação que uniu suas experiências de irmandade de alcoólicos anônimos a outras influências filosóficas, pragmáticas e psicológicas, a fim de lançar e desenvolver o programa da Synanon. Ainda de acordo com Fracasso, o que distingue a comunidade terapêtica Synanon da irmandade de alcoólicos anônimos "são os aspectos relativos ao ambiente residencial do programa, sua estrutura organizacional, o perfil dos participantes, bem como suas metas, sua filosofia e sua orientação psicológica" (2011, p. 62 ). Neste modelo de comunidade terapêutica, os indivíduos permaneciam 24 horas em ambiente residencial; sendo assim, ficavam afastados de elementos sociais, circunstanciais e interpessoais da comunidade mais ampla que poderiam influenciar o uso de substâncias.
É importante, também, destacar que, em 1976, o National InstituteonDrug Abuse (NIDA) patrocinou nos Estados Unidos uma conferência de planejamento das comunidades terapêuticas, em que "profissionais reuniram-se para deliberar e esclarecer a natureza e o propósito das CTs como tratamento para o abuso de substâncias psicoativas (SPA)" (FRACASSO, 2011, p. 63). Ao longo das últimas décadas, profissionais e participantes de comunidades terapêuticas de todo o mundo enfrentam a tarefa de definir esta modalidade de tratamento, com intensa participação nas discussões realizadas pelas Federações Nacionais, Internacionais e Mundial de Comunidades Terapêuticas (FRACASSO, 2011).

As comunidades terapêuticas são:

Instituições provadas, sem fins lucrativos e financiadas, em parte, pelo poder público. Oferecem gratuitamente acolhimento para pessoas com transtornos decorrentes do uso, abuso ou dependência de drogas. São instituições abertas, de adesão exclusivamente voluntária, voltadas a pessoas que desejam e necessitam de um espaço protegido, em ambiente residencial, para auxiliar na recuperação da dependência à droga. $\mathrm{O}$ tempo de acolhimento pode durar até 12 meses. Durante esse período, os residentes devem manter seu tratamento na rede de atenção psicossocial e demais serviços de saúde que se façam necessários (COMUNIDADES..., [20--]).

Estas comunidades devem garantir o respeito à pessoa e à família, independente da etnia, do credo religioso, da ideologia, da nacionalidade, da orientação sexual, de antecedentes criminais ou da situação financeira (COMUNIDADES..., [20--]). Devem, também, garantir ao usuário e ao seu responsável a orientação clara sobre as normas e rotinas da instituição, incluindo os critérios sobre visita e comunicação com familiares e amigos, bem como garantir a permanência voluntária, a vedação 
de qualquer forma de contenção física, isolamento ou restrição à liberdade, a possibilidade de o usuário interromper a permanência a qualquer momento e a privacidade quanto ao uso de vestuário próprio e de objetos pessoais.

De acordo com o Observatório Brasileiro de Informações sobre Drogas (OBID, 2007), o programa desenvolvido no período de tratamento na comunidade terapêutica tem como objetivo ajudar o dependente químico a se tornar uma pessoa livre por meio da mudança de seu estilo de vida, pois a comunidade terapêutica é uma ajuda eficaz para quem tem a necessidade de liberar as próprias energias vitais para poder ser um homem em seu sentido pleno, adulto e autônomo, que seja capaz de realizar um projeto de vida sem a ajuda de substâncias psicoativas e de aprender a estar de bem consigo mesmo. Além disso, para o tratamento ocorrer corretamente, a equipe deve acreditar que, independente de qualquer comportamento que o dependente tenha tido, este pode mudar, assim como o dependente deve acreditar em sua mudança. $\mathrm{O}$ ambiente deve possibilitar a aprendizagem social e a oportunidade de interagir, escutar, aprender, projetar, envolver-se e crescer de maneira que reflita no potencial individual e coletivo dos que fazem parte da comunidade terapêutica.

O comportamento começa a mudar através da auto-iniciativa do residente. Como ele vem de uma vivência de sub-cultura (valores não aceitos pela sociedade), devemos solicitar que ele exercite agir com honestidade, pontualidade, solidariedade, etc., (valores aceitos pela sociedade) para que os internalize e os vivencie através das mudanças de estilo de vida. A dinâmica desse processo depende, em parte, da organização social da CT e, em parte, da motivação das pessoas envolvidas (OBID, 2007, s/p).

\subsection{Trabalho voluntário}

“O voluntário é um jovem ou adulto que, por interesse pessoal e espírito cívico, dedica parte de seu tempo, sem remuneração alguma, a atividades voltadas ao bem estar social ou a outros campos" (ORGANIZAÇÃO DAS NAÇÕES UNIDAS, 2014, s/p).

De acordo com o art. $1^{\circ}$ da Lei n. ${ }^{\circ} 9.608$, de 18 de fevereiro de 1998 , que regulamenta a atividade voluntária no Brasil, a atividade voluntária é:

A atividade não remunerada, prestada por pessoa física a entidade pública de qualquer natureza, ou a instituição privada de fins não lucrativos que tenha objetivos cívicos, culturais, educacionais, científicos, recreativos ou de assistência social, inclusive mutualidade (BRASIL, 1998).

Segundo Hudson (1999 apud SOUZA, 2012, p. 98), o setor voluntário oferece três contribuições importantes para a sociedade:

1. Representação, por contribuir para o desenvolvimento de políticas públicas e para os processos de integração e coesão social;

2. Inovação, por incorporar ações que transformam o meio social, desenvolvendo sujeitos e comunidades; e,

3. Cidadania, por ser realizada a partir de ações de natureza informal e, mesmo assim, sob elevado grau de eficiência e eficácia.

Em relação aos aspectos considerados importantes ao voluntariado, existem pelo menos quatro: as características demográficas do fenômeno de voluntariado, que podem incluir a distribuição geográfica, o estatuto social, a educação e/ou a personalidade dos voluntários; as motivações que conduzem ao volunta- 
riado; o comportamento dos voluntários na organização; e as recomendações para uma gestão efetiva de voluntários, sendo estas duas últimas asáreas menos exploradas (JÄGER; SCHMIDT; BEYES, 2007 apud FERREIRA, 2008).

Segundo Latham e Pinder (2005 apud FERREIRA, 2008, p. 45), "a motivação é um processo psicológico complexo que resulta de uma interação entre o indivíduo e o ambiente que o rodeia". Sendo assim, o indivíduo motivase para o trabalho de acordo com suas forças enérgicas, determinando a forma, direção, intensidade e duração deste.

Desse modo, ao iniciar um trabalho voluntário, o indivíduo voluntário é guiado de acordo com seus valores, seus traços de personalidade, suas necessidades fisiológicas, o contexto em que está inserido, a questão monetária e o tempo disponível. Segundo Wilson e Pimm (1996 apud FERREIRA, 2008, p. 47), "a vida útil de um voluntário pode ser limitada por um propósito, por uma organização específica ou por um determinado período de tempo". Os voluntários não esperam um benefício financeiro, mas têm o desejo de que seu trabalho seja apreciado e reconhecido.

\section{Método}

Esta pesquisa é de natureza qualitativa, tendo sido desenvolvida por meio de entrevistas, com questões semiestruturadas. Essas questões foram aplicadas a cincoex-usuários de drogas que trabalham voluntariamente na comunidade terapêutica Fazenda da Esperança em Casca, Rio Grande do Sul, local escolhido por conveniência.

No primeiro momento, as entrevistas foram gravadas e, após, transcritas para a elaboração da análise. O procedimento ocorreu na Fazenda da Esperança, de modo que cada participante, antes de ser entrevistado, assinou o Termo de Consentimento Livre e Esclarecido (TCLE) para garantir o anonimato e a confiabilidade das informações obtidas.
A análise dos dados coletados foi realizada por meio da técnica de análise de conteúdo proposta por Bardin (1977). Esse procedimento é composto de três etapas: 1) pré-análise; 2) exploração do material; e 3) tratamento dos resultados, inferência e interpretação. As categorias de análise foram escolhidas a posteriori, ou seja, depoisda realização das entrevistas.

\section{Apresentação e análise dos dados}

Após a análise dos dados coletados, optou-se por criar quatro categorias: motivação, espiritualidade, dificuldades encontradas e reconhecimento. Entrevistaram-se cinco participantes, sendo eles Apolo (deus do sol - princípio da vida), 38 anos, foi usuário de cocaína, maconha, álcool e crack por 20 anos, é voluntário na comunidade há sete anos e meio e busca dar uma nova vida para os internos livrarem-se da dependência; Hélio (antigo deus do sol - visava proporcionar luz aos deuses e mortais), 25 anos, foi usuário de cocaína, crack, maconha e cola de sapateiro por 12 anos, é voluntário na comunidade há um ano e meio e busca, em sua forma de cuidado e acolhimento, dar a chance do recomeço para os internos que chegam sem esperança; Fênix (ave de grande força - após sua morte, entra em autocombustão e depois renasce das cinzas), 33 anos, foi usuário de crack por 12 anos, é voluntário na comunidade há seis meses, recaiu três anos após a primeira internação - chegando a ficar três dias em uso da droga sem alimentar-se, trancado em um quarto -, renasceu após a segunda internação e agora busca ajudar outros usuários a renascerem; Ares (deus da guerra - agressivo e sanguinário, impopular entre os deuses e os seres humanos), 20 anos, foi usuário de maconha, crack, heroína e cocaína por dez anos, é voluntário na comunidade há dois anos e meio, foi integrante das Forças Armadas Revolucionárias da Colômbia (FARC) aos 
doze anos, assassinou 17 pessoas e foi encontrado quase morto na rua por uma senhora que o apresentou à comunidade; e Eros (deus do amor), 26 anos, foi usuário de cocaína e dolantina por um ano, é voluntário na comunidade há sete meses, buscava no uso da droga encontrar companheiros que lhe dessem amor e satisfação afetiva, passou por três reabilitações em um ano e hoje encontrou $\mathrm{o}$ amor que the carecia no cuidado com o outro dentro da comunidade. Os nomes utilizados neste artigo são fictícios, visando preservar a integridade dos participantes, sendo todos baseados na mitologia grega e relacionados às características de cada entrevistado.

\subsection{Motivação}

Davidoff (2001) define motivação como um estado interno que pode resultar de uma necessidade. É um ativador ou despertador de comportamento dirigido para a satisfação da necessidade instigadora. Conforme a autora, há dois tipos de motivação: aquela que é estabelecida principalmente pela experiência, conhecida apenas como motivação; e aquelas que surgem para satisfazer as necessidades básicas relacionadas à sobrevivência, que são conhecidas como impulsos. Para Davidoff (2001), há ainda dois modelos de motivação: o homeostático, que sugere que o corpo tem padrões de referência para cada uma de suas necessidades, e, quando surge uma necessidade, esta ativa um motivo para manter o equilíbrio, estando, assim, voltada à autorregulação do corpo; e o modelo de incentivo, que sugere que experiências e incentivos alteram cognições e emoções levando à motivação, a qual, por sua vez, aciona o comportamento, alterando emoções e aumentando ou diminuindo o nível de motivação.

Percebeu-se, ao longo das entrevistas, que a busca dos voluntários está ligada a ajudar o outro, mas também a continuar a sua recuperação, pois creem que, como a comunidade os ajudou a re- cuperarem-se, eles devem retribuir esta ajuda a partir do trabalho voluntário, a fim de auxiliar outros dependentes químicos.

Tá dentro da Fazenda da Esperança, vivendo esse estilo de vida e abraçando um carisma nascido dentro de uma comunidade terapêutica, mas que, além de ter salvo a minha vida, me torna veículo também pra que outros encontrem esse caminho.[...] Principalmente porque essa vida me faz bem, porque essa vida me converte, me recupera todo dia, me dá oportunidade de amadurecer, de ser realmente assim um ser humano por excelência (Apolo).

É ajudar e também ser ajudado né, porque eu ajudo eles, mas eles também me ajudam, porque eu terminei meu ano de recuperação, porque eu sou voluntário eu também tenho crises, eu também tenho dificuldades, então tem muitas vezes que eu sou aquela voz de apoio pra eles, mas tem muitas vezes que eles são pra mim né (Ares).

Ressalta-se também que, além de continuarem recuperando-se, os voluntários buscam dar ao outro o que receberam, pois, como se sentiram bem quando acolhidos, desejam retribuir esse amor gratuito que acreditam ter recebido. Sendo assim, para Sanchez e Nappo (2008), em relação ao acolhimento do grupo, o contato físico sem preconceitos impressiona e valoriza os dependentes químicos, de modo que estes são colocados no mesmo nível de quem os acolhe e, além disso, ouvem relatos das pessoas que, assim como eles, também erraram e conseguiram se redimir.

Sempre de ser bem tratado, sempre me darem atenção, e isso foi crescendo dentro de mim e quando eu fiz o meu ano, 2008/2009, na época o responsável era o padre Antônio, e quando terminei o ano ele me fez o convite de ser padrinho (Fênix). 
Dar de graça o que recebeu de graça, e eu fui gostando da fazenda né, e aquela coisa de viver também (Eros).

Dar de graça o que tu recebeu de graça (Ares).

É possível perceber, ainda, que há uma crença dos voluntários de que eles se recuperarão totalmente da dependência química se fizerem este trabalho. Segundo Beck (2013), as crenças sobre si mesmo, outras pessoas e seus mundos começam a desenvolver-se ainda na infância, sendo consideradas como uma verdade absoluta para a pessoa, que acredita que as coisas são da forma que ela pensa. As crenças centrais influenciam a sua visão de uma situação, alterando o modo como ela pensa, sente e se comporta.

Ajudar as pessoas e a mim mesmo, sempre e porque o trabalho voluntário... nós falamos na fazenda que continuamos nos recuperando né (Eros).

Mas a minha sobriedade, pra mim me manter limpo é, só tá através dessa experiência como voluntário. [...] Eu fui pra casa tentei, reconstruir minha vida, trabalhar, mas aquela coisa de não ter cumprido esse tempo de voluntario sempre ficou dentro de mim. [...] Eu vejo que a minha sobriedade, a reconstrução da minha vida tá dentro desse voluntariado, tá dentro desse trabalho que eu tô exercendo e deixar com que Deus conduz meu caminho (Fênix).

Percebe-se que esta comunidade já os faz acreditar que eles continuarão em um processo de recuperação e que Deus escolhe os seus caminhos. Segundo Sanchez e Nappo (2008, p. 269):

A fé promove a qualidade de vida. A adoção de referenciais da religião faz com que o fiel confie na proteção de Deus e respeite as normas e valores impostos pela religião, melhorando a qualidade de vida dos adeptos. [...]
O enfrentamento das dificuldades, a partir da perspectiva espiritual apoiado na fé, acaba proporcionando afastamento natural de atitudes contrárias a moral difundida pela religião. Além disso, o fato de se contar com a ajuda irrestrita de Deus gera um amparo constante, conforto e bem-estar.

A partir disso, nota-se que a fé promove o bem-estar nos voluntários, fazendo - os faz acreditar que sua recuperação depende dessa doação voluntária, como se não houvesse outras possibilidades para alcançarem esta conquista. Sendo assim, esta crença os impulsiona a continuarem ajudando o outro para conseguirem a recuperação plena da dependência química.

Quando terminei o ano, me fizeram o convite de ser padrinho voluntário e eu fiquei três meses e assim, da minha livre e espontânea vontade, sem falar com ninguém, simplesmente peguei minhas coisas e fui embora. A proposta era de um ano e eu acabei ficando somente três meses. Eu fui pra casa tentei reconstruir minha vida, trabalhar, mas aquela coisa de não ter cumprido esse tempo de voluntário sempre ficou dentro de mim. [...] Antes da recaída eu tive várias oportunidades de vir até a fazenda fazer visita ou mesmo que fosse nos dias fora de visita, só pra visita e tals, mas nunca vim, aí quando eu tive a recaída eu lembrei da fazenda novamente e foi por causa disso que agora, depois que eu fiz meu recomeço de quatro meses, novamente, o Fabinho que já era responsável e a Maria me fizeram o convite e eu não tive dúvida que Deus quer que eu faça esse trabalho (Fênix).

Pode-se perceber que, conforme a fala do entrevistado, que voltou para casa após a primeira recuperação, mas sentiu-se incomodado por não ter feito o voluntariado. Após a segunda reabilitação na mesma comunidade, instaurou-se uma crença para este voluntário de que a sua recuperação dependia do voluntariado que ele estava exercendo. 


\subsection{Espiritualidade}

A religião católica oferece dois recursos terapêuticos exclusivos: a confissão e a eucaristia. A confissão é considerada terapia espiritual. Quando o sacerdote pronuncia a absolvição sacramental, traça o sinal da cruz e declara que o pecadorestá perdoado, o indivíduo é tocado por uma sensação de ter saído da condição de pecador e evoluído para a de servo de Jesus, melhorando sua autoestima (SANCHEZ; NAPPO, 2008). Segundo o Estatuto da Fazenda da Esperança,

Para garantir o espírito de família e a esperança sempre renovada, o membro vive a espiritualidade do Evangeho, como radicalidade, comunicando entre si as experiências feitas à luz da palavra de Deus, de forma que se realize em suas vidas e na de sua comunidade a frase do evangelho: " $\mathrm{E}$ $o$ verbo se fez carne e habitou entre nós" (Jó 1,14). Da mesma forma, o membro vive à luz da Palavra de Deus o amor recíproco e a escolha de Jesus abandonado, contribuindo para que as Fazendas da Esperança se tornem "Santuários da Nova Evangelização" a serviço da comunidade eclesial (2010, p. 31-33).

Nas comunidades terapêuticas católicas, a confissão exime o dependente de drogas da culpa de seus erros passados e torna possível um futuro novo, como se o indivíduo recomeçasse sua vida a partir de um novo ponto zero. $\mathrm{Na}$ comunhão, os entrevistados creem que estão recebendo parte de Jesus, que os protegerá da vontade de consumir drogas. Sendo assim, percebe-se como os voluntários acreditam que estão recuperados e que estão livres da culpa dos erros passados, o que faz com que sintam que se tornaramo caminho para os outros e até mesmo um exemplo a ser seguido (SANCHEZ; NAPPO, 2008).

A espiritualidade é a base do tratamento para a dependência química nesta comunidade terapêutica, fator que influencia o pensamento e no comportamento dos voluntários. Além disso, pode-se perceber que as crenças que eles têm sobre a sua recuperação e sobre a comunidade em si podem influenciar a forma como eles sairão dela e como agirão, levando-os a exercerem um maior controle dos seus atos:

O tesouro que tenho não passa, mas sei que tudo aquilo que me cerca no mundo, até os meninos que vêm e que vão, tudo passa, mas esse tesouro que encontrei ele não passa, que é a vida em Cristo, que é a vida no amor, na simplicidade, no desapego, na vida que preenche e que não passa (Apolo).

Porque a realidade na fazenda é uma, lá fora é outra né, então aqui eu estou dentro da fazenda, lá fora eu vou ter que levar a fazenda dentro de mim, pra poder lutar contra o mundo, pra poder ir todo dia e colocar em prática tudo que aprendi aqui, lá fora né, tentar ser uma pessoa cada dia como eu sou aqui né (Ares).

Savio e Bruscagin (2008, apudFUCHS; HENNING, 2011) destacam que a espiritualidade influencia a forma como os indivíduos podem lidar com as adversidades, as experiências de dor e de sofrimento. A religiosidade atua, assim, como prescritora e proibidora de comportamentos cotidianos, estimulando os comportamentos saudáveis e fazendo a pessoa pensar sobre sua forma de comer, beber, conduzir automóveis, ter relações sexuais, usar substâncias lícitas e ilícitas, seguir prescrições médicas, educar os filhos e relacionar-se com seu parceiro (SAVIO; BRUSCAGIN, 2008, apud FUCHS; HENNING, 2011).

Hoje eu percebo um amadurecimento muito grande, não só na questão do lado humano, mas nos aspectos que nos cercam. [...] Lembro que, quando decidi optar pelo celibato, havia uma dúvida: mas com relação à sexualida- 
de, com relação ao afetivo, ao emocional; mas é o retorno desse amor gratuito, quando retorna pra nós, ele é tão intenso, tão divino, que transcende ao humano, ao divino, humano até compreendendo na sua psique, no emocional, no físico principalmente no divino, quando esse amor retorna, parece que o humano mergulha nessa realidade (Apolo).

Os voluntários seguem as regras da comunidade, acreditando que a espiritualidade supre todas as suas necessidades, pois sentem o amor gratuito. "As crenças religiosas fornecem apoio através do reforço da aceitação, resistência e resiliência, gerando paz, autoconfiança, perdão a si próprio, e as demais pessoas, doação e autoimagem positiva" (MOREIRA-ALMEIDA; LOTUFO NETO; KOENIG, 2006 apud FUCHS; HENNING, 2011, p. 3). As crenças são fundamentais para estes indivíduos se manterem dentro do voluntariado, pois, se não houvesse a crença de que eles recebem a recompensa espiritual, presume-seque eles não conseguiriam suportar o não suprimento destas necessidades.

\subsection{Dificuldades encontradas}

Segundo Robbins (2004), a personalidade de um indivíduo adulto é a soma total das maneiras como reage e interage com as demais, ou seja, é resultado de diversos fatores ambientais e hereditários, moderados pelas condições situacionais. A abordagem hereditária define que a personalidade de um indivíduo está na estrutura molecular de seus genes, sendo influenciada pelos perfis biológicos, fisiológicos e psicológicos dos pais. $\mathrm{O}$ ambiente influencia a personalidade de acordo com a nossa cultura, a qual estabelece normas, atitudes e valores, que são transmitidos de geração em geração, influenciando a forma como somos criados, as condições de infância, as normas familiares, as amizades, os grupos sociais etc. Já a situação em que o indivíduo é colocadoinfluencia os efeitos da hereditariedade e do ambiente sobre a personalidade, pois uma pessoa pode mudar conforme a situação. Sendo assim, pode-se perceber o modo como a personalidade de cada uma das pessoas da comunidade terapêutica pode influenciar a convivência entre os voluntários.

Olha, muitas vezes é difícil lidar com várias pessoas, porque eu sou uma pessoa de temperamento muito forte, porque eu muitas vezes tem outra pessoa que também tem o temperamento muito forte e muitas vezes duas pessoas de temperamento forte juntas vai dar explosão (Ares).

Quando as dificuldades se apresentam, elas se apresentam na questão da convivência, sabe. [...] Mas são coisas que acontece na fazenda e sempre vai acontecer, de ter aquelas pessoas que vem como voluntario e às vezes acabam entrando num certo comodismo, entendeu, e eu sofro com isso, entendeu (Eros).

Nem sempre as relações com o outro são fáceis, ainda mais em uma comunidade onde os indivíduos que nela vivem têm pouco acesso a outras pessoas e acabam sendo obrigados a conviver com pessoas de diversas culturas e criações, que, muitas vezes, têm temperamentosdiferentes. Na comunidade,todos os integrantes são do gênero masculino, o que também pode afetar a convivência, visto que, segundo as normas que regem esta comunidade terapêutica, os mesmos devem se privar de sua satisfação sexual quando resolvem ser voluntários e dedicarem-se à comunidade.

A convivência com o outro também está ligada às emoções, definidas por Robbins (2004) como sentimentos intensos direcionados a alguém ou alguma coisa. Estas emoções podem se transformar em humores, que podem gerar um sentimento relacionado à pessoa que the causou a emoção. Para 
trabalhar bem com outras pessoas, deve-se possuir não apenas competências técnicas para realizar suas funções, mas também competências emocionais.

Em relação às dificuldades encontradas, também foi destacada pelos voluntários a dificuldade em lidar com os próprios sentimentos frente ao outro e compreender o outro como um ser humano com defeitos. Tal contato é complexo devido, também, à dificuldade do voluntário em lidar com o seu sentimento diante de algo que não considera como sendo aceitável:

$\mathrm{Na}$ fazenda me manter paciente, às vezes eu me explodo, sou explosivo, muito rhaur, eu sou muito metódico... [...] O equilíbrio, entender um pouco o outro, eu tenho essa dificuldade ainda... (Eros).

Mas daí eu tenho que me testar, daí eu tenho que me pôr naquele momento que acontece aqueles fatos, aonde está meu voluntariado?, me igualar dele ou fazer menos que ele. [...]Porque a gente tem um ponto fraco né, e a gente tenta mais por esse ponto fraco né ele tenta te cutucar, mas vai de mim me deixar cutucar por ele. Porque tudo depende de mim né (Ares).

Muitas vezes, as dificuldades que surgem na relação com o outro são causadas pelo não equilíbrio da relação consigo mesmo. Portanto, é fundamental o equilíbrio próprio para que se possa estar de bem com os outros. Sendo assim, para ter uma relação saudável com o outro, é preciso, primeiramente, aprender a lidar com os próprios sentimentos, para que estes não influenciem a forma em que os relacionamentos interpessoais possam acontecer. Os indivíduos apresentam maneiras pessoais para lidar com seus sentimentos e suas emoções, maneiras estas que entram em contato com outros indivíduos que possuem suas próprias maneiras. Assim sendo, o que pode facilitar ou dificultar a convivência e as relações entre os voluntários é o autoconhecimento e o conhecimento do outro, que fazem com que se amplie a compreensão de como cada um age.

\subsection{Reconhecimento}

Segundo Siqueira e Gomide (2004, apud BENDASSOLLI, 2012), o reconhecimento é o elemento-chave da relação do sujeito com o trabalho e a organização, com implicações diretas nos processos motivacionais e nas percepções de reconhecimento e valorização. Segundo as ideias de Hegel (1992 apud BENDASSOLLI, 2012), o trabalho representa um tipo de interação primariamente dependente do reconhecimento, pois é marcado pela atividade dos outros. Percebe-se que, em suas falas, os voluntários se sentem reconhecidos pelo trabalho que estão exercendo:

Me sinto reconhecido, é, bem honesto sabe, bem no fundo do meu coração eu posso te dizer que eu me sinto reconhecido... (Fênix).

E eu sei que as pessoas reconhecem... pra mim a maior satisfação não precisa 'ah eu reconheço teu trabalho', só de tu ver a alegria dos meninos, tu ouvir um obrigado eu fico contente. [...] eles não precisam dizer um obrigado isso, as vezes um gesto, os gestos que eles fazem pra nós, pra mim é totalmente suficiente (Ares).

Brun e Dugas (2005 apud BENDASSOLLI, 2012) descrevem quatro dimensões do reconhecimento no trabalho: o reconhecimento da pessoa, de concepção humanista, direciona-se ao indivíduo em si; o reconhecimento pelos resultados, de base comportamental, destaca os resultados assumindo a forma de recompensas financeiras; o reconhecimento pelo esforço, que estipula que os resultados nem sempre são proporcionais ao esforço investido, independente de recompensas, sendo simbólico; e o reconhecimento pelas 
competências. Percebe-se que os entrevistados se sentem reconhecidos a partir da terceira esfera (reconhecimento pelo esforço), pois, em suas falas, demonstram ser simbólica a forma com que são reconhecidos, manifestada por meio de abraço ou mesmo de um agradecimento verbal:-

Busco além do amor que eu dou, eu acabo sendo amado também né, acabo sentindo, me sentindo bem fazendo isso, porque muitas vezes chega alguém te agradece, muitas vezes nem agradece, muitas vezes tu sente né, vê a pessoa bem, vê a pessoa voltando a vida dela (Hélio).

Sim, me sinto muito reconhecido, aquilo assim é, aqui na fazenda é mais afetivo né. [...] aqui é um abraço, um obrigado, olha ficou bonito o que você fez né, levanta a autoestima, vai falar que quem não gosta e eu... a parte de reconhecimento aqui é assim, a parte mais afetiva mesmo (Eros).

Em se tratando de um trabalho voluntário, o reconhecimento manifesta-se de forma simbólica, pois, como o voluntariado é uma doação para o outro e também para a instituição, o reconhecimento não vem em forma de incentivo financeiro - salários - ou de mudança de cargo - promoções -, como normalmente acontece em empresas e outras instituições. Percebeu-se nas entrevistas o quanto esta forma de reconhecimento é valorizada pelos próprios voluntários, o que os estimula a continuarem ajudando ao outro e a buscarem estratégias para ajudarem a si mesmos, pois quanto mais se sentirem reconhecidos e motivados, maiores são as chances de continuarem o seu voluntariado, ajudando ao outro e também continuando a sua reabilitação.

\section{Considerações finais}

Nem todo ser humano está disposto a enfrentar uma parte de sua história que evoca lembranças e sentimentos dolorosos. São admiráveis estas pessoas que decidem se doarem ao outro, deixando de lado a sua família, o conforto do lar e a sua independência para viver de forma voluntária em uma comunidade religiosa.

A comunidade terapêutica observada segue os princípios franciscanos, de modo que os voluntários devem viver com o que a comunidade thes proporciona diante do trabalho realizado por eles e sem poder ter relação afetiva com pessoas do sexo oposto dentro daquele espaço. A espiritualidade é o preceito fundamental do tratamento, sendo realizadas orações todos os dias, a fim de buscar o perdão de Deus por seus atos e também a recuperação plena da dependência química.

Percebeu-se a falta de um acompanhamento psicológico nesta comunidade, pois há situações de relações interpessoais com as quais o voluntário não sabe lidar, até mesmo porque, em diversos momentos, voluntário identifica nos usuários em tratamento uma realidade já vivenciada por ele, o que acaba gerando um conflito com os seus próprios sentimentos. Em relação a isso, a maioria dos voluntários nunca fez um acompanhamento psicológico e tem dificuldades em lidar com os seus sentimentos, principalmente quando se encontra diante de alguma situação que lhe causa dor ou raiva, momento em que acabam agindo por impulso e gerando mais conflitos.

Durante as entrevistas, os voluntários falaram abertamente sobre todos os assuntos questionados, não se negando a responder nenhum dos temas suscitados por mais difíceis que pudessem ser. Em uma das entrevistas, o voluntário sensibilizou-se ao relatar uma situação delicada que passou em seu tempo de trabalho na comunidade terapêutica, quando viu um usuário chegar da mesma forma como ele chegou ao se internar para o tratamento: morador de rua, com as roupas rasgadas, todo sujo e em forte crise de abstinência. De acordo com o voluntário, logo que este interno 
chegou à comunidade, ele foi acolhê-lo, enquanto muitos o olhavam com repugnância e se afastavam. Descreveu esse momento como o mais difícil passado como voluntário, de modo que, após acolher e auxiliar o novo interno com o banho, sentiu a necessidade de retirarse e trancou-se no quarto para chorar. Histórias como essa ajudam a compreender um pouco mais a doação que os voluntários realizam neste trabalho na comunidade terapêutica, bem como reforçam ainda mais a certeza de como a presença de um profissional da Psicologia poderia auxiliá-los, otimizando o serviço oferecido nestas comunidades.

Ao longo deste trabalho, chamou atenção o amor e o cuidado que esses voluntários têm um com o outro - que cada um deles desenvolve uma função diferente na comunidade, buscando o cuidado com o outro e o bom funcionamento daquele espaço. Este cuidado ao outro é importante quando se trata de uma reabilitação, pois a grande maioria dos internos vem de uma realidade difícil, em que muitos já foram até moradores de rua. Quando chegam à comunidade, geralmente estão psicologicamente fragilizados, não confiando em ninguém uma vez que já perderem a confiança inclusive de seus familiares e amigos. Então, este cuidado vai aproximando o voluntário do interno, criando um vínculo que pode ser primordial para o sucesso do tratamento para a dependência química.

Ressalta-se, ainda, que todos os voluntários expuseram ter como motivação para seu trabalho a ajuda ao outro, bem como a continuação do seu próprio tratamento. Todos sabem que, enquanto estiverem na comunidade, conseguirãose manter longe das drogas e dos fatores que os levaram à dependência e que, quando saírem da comunidade, estarão propensos às chances de depararem-se com a droga novamente.

\section{Referências}

1. AMERICAN PSYCHIATRIC ASSOCIATION. Manual Diagnóstico e Estatístico de Transtornos Mentais. 4. ed. Porto Alegre: ARTMED, 2002.

2. AZEVEDO, R. C. S. de; OLIVEIRA, K. D. Poliusuários de Substâncias Psicoativas. In: DIEHL, A.; CORDEIRO, D. C.; LARANJEIRA, R. Dependência Química: Prevenção, tratamento e políticas públicas. Porto Alegre: Artmed, 2011. p. 119-125.

3. BARDIN, L. Análise de Conteúdo. Lisboa: Edições 70, 1977.

4. BECK, J. S. Terapia CognitivoComportamental: teoria e prática. 2 . ed. Porto Alegre: Artmed, 2013.

5. BENDASSOLLI, P. F. Reconhecimento no Trabalho: perspectivas e questões contemporâneas. Psicologia em Estudo, Maringá, v. 17, n. 1, p. 3746, 2012.

6. BRASIL. Lei $\mathrm{n}^{\circ} 9.608$ de 18, de fevereiro de 1998. Dispões sobre o serviço voluntário e dá outras providências. Diário Oficial da República Federativa do Brasil, Brasília, DF, 19 fev. 1998. Disponível em: <http://www.planalto.gov.br/ccivil 03/leis/L9608.htm> Acesso em: 09 mai. 2014.

7. COMUNIDADES Terapêuticas. Disponível em: <http://www.brasil.gov.br/ observatoriocrack/cuidado/comunidades-terapeuticas.html> Acesso em: 14 abr. 2014.

8. DAVIDOFF, L. L. Introdução à Psicologia. 3. ed. São Paulo: Pearson Makron Books, 2001.

9. FAMÍLIA DA ESPERANÇA. Estatuto. Guaratinguetá, 2010.

10. FERREIRA, M.; PROENÇA, T.; PROENÇA, J. F. As Motivações do Trabalho Voluntário. Revista Portuguesa e Brasileira de Gestão, Rio de Janeiro, p. 43-53, 2008. 
11. FONSECA, V. A. da S.; LEMOS, T. Farmacologia na Dependência Química. In: DIEHL, A. CORDEIRO, D. C.; LARANJEIRA, R. Dependência Química: Prevenção, tratamento e políticas públicas. Porto Alegre: Artmed, p. 2534, 2011.

12. FRACASSO, L. Comunidades Terapêuticas. In: DIEHL, A.; CORDEIRO, D. C.; LARANJEIRA, R. Dependência Química: Prevenção, tratamento e políticas públicas. Porto Alegre: Artmed, p. 61-69, 2011.

13. FUCHS, G. C.; HENNING, M. C. A Influência da Espiritualidade na Recuperação de Dependentes Químicos. Disponível em: $<$ http://www.uniad. org.br/images/stories/A INFLUENCIA_DA_ESPIRITUALIDADE_NA RECUPERACAO DE DEPENDENTES_QUIMICOS.pdf $>$. Acesso em: 08 out. 2014.

14. MARQUES, A. C. P. R.; RIBEIRO, M. (Orgs.). Guia Prático sobre Uso, Abuso e Dependência de Substâncias Psicotrópicas para Educadores e Profissionais da Saúde. São Paulo: Imprensa Oficial, 2006.

15. OBSERVATÓRIO BRASILEIRO DE INFORMAÇÕES SOBRE DROGAS (OBID). Tratamento, Modelo, Comunidade Terapêutica. Disponível em: <http://www.obid.senad. gov.br/portais/OBID/conteudo/index. php?id_conteudo $=11420 \&$ rastro $=$ TRATAMENTO $\% 2$ FModelos/Comunidade+Terap $\%$ C $3 \%$ AAutica $>$. Acesso em: 16 abr. 2014.

16. ORGANIZAÇÃO DAS NAÇÕES UNIDAS (ONU). O Trabalho Voluntário e a ONU, 2014. Disponível em: $<\mathrm{http}$ //nacoesunidas.org/vagas/voluntariado/> Acesso em: 06 dez. 2014.

17. ORGANIZAÇÃO MUNDIAL DE SAÚDE (OMS). Classificação de Transtornos Mentais e de Comportamento da CID-10. Porto Alegre: Artmed, 1993.
18. PRATTA, E. M. M.; SANTOS, M. A. dos. O processo saúde-doença e a Dependência Química: Interfaces e evolução. Psicologia: Teoria e Pesquisa, v. 25, n. 2, p. 203-211, 2009.

19. ROBBINS, S. P. Comportamento Organizacional. 9. ed. São Paulo: Prentice Hall, 2002.

20. SANCHEZ, Z. Van der M.; NAP$\mathrm{PO}, \mathrm{S}$. A. Intervenção Religiosa na Recuperação de Dependentes de Drogas. Revista Saúde Pública, v. 42, p. 265 72, 2008.

21. SOUZA, W. J. de; MEDEIROS, J. P. de. Trabalho voluntário: Motivos para sua realização. Revista de Ciências da Administração, v. 14, n. 33, p. 99-102, 2012.

22. UNIVERSIDADE ABERTA DO SISTEMA ÚNICO DE SAÚDE (UNASUS). Abordagem da Dependência Química. Disponível em: $<$ http://www. unasus.unifesp.br/biblioteca_virtual/ esf/1/casos complexos/Vila Santo Antonio/Complexo_12_Vila_Abordagem dependencia.p $\overline{\mathrm{d} f}>\overline{\mathrm{A}} \mathrm{cesso}$ em: 02 jun. $\overline{2} 014$ 